\title{
Crescimento, consumo hídrico e composição mineral de alface cultivada em hidroponia com águas salinas
}

\author{
Dalva Paulus ${ }^{*}$, Eloi Paulus ${ }^{2}$, Gilmar Antônio Nava ${ }^{3}$, Cláudia Andrade Moura ${ }^{4}$
}

\begin{abstract}
RESUMO
Objetivou-se, com este trabalho, avaliar o crescimento, o consumo hídrico e a extração de nutrientes, por alface (Lactuca sativa L.) em sistema hidropônico NFT (fluxo laminar de nutrientes), com a utilização de águas salinas no preparo da solução nutritiva e reposição da lâmina diária evapotranspirada. Foram conduzidos dois experimentos, em ambiente protegido. O delineamento experimental foi em blocos ao acaso, sendo estudados os efeitos de cinco níveis de salinidade da água, utilizando-se $\mathrm{NaCl}$. O aumento da salinidade da água reduziu, de forma linear, o crescimento e o consumo hídrico da alface. A salinidade reduziu a concentração de macronutrientes na parte aérea, mas não se observaram sintomas de deficiência nutricional. O rendimento (massa de matéria fresca da parte aérea) foi reduzido entre 6 e $6,5 \%$ por $\mathrm{dS} \mathrm{m}^{-1}$, no primeiro e segundo cultivo, respectivamente. Os resultados obtidos em sistema de cultivo NFT podem indicar a possibilidade do uso da água salina como alternativa para produção de hortaliças, para produtores que têm disponibilidade restrita de água doce, porém, com redução de produtividade.
\end{abstract}

Palavras-chave: Lactuca sativa L., salinidade, condutividade elétrica

ABSTRACT

\section{Growth, water consumption and mineral composition of lettuce in hydroponic system with saline water}

The objective of this study was to evaluate the growth, water consumption and extraction of nutrients of lettuce (Lactuca sativa L.) in a NFT (nutrient film technique) in hydroponic system using saline water. Two experiments were conducted in a protected environment. The experiment was arranged in a completely randomized design with five replications and five levels of salinity in the irrigation water using $\mathrm{NaCl}$. Increasing water salinity reduced the growth and water consumption of lettuce linearly. The salinity reduced the macronutrient concentration, but symptoms of nutritional deficiency were not observed. The lettuce yield (shoot fresh matter) was reduced by $6 \%$ and $6.5 \%$ per $\mathrm{dS} \mathrm{m}^{-}$ ${ }^{1}$, in the first and second crops, respectively. The results obtained in the NFT system indicate the possibility of using saline water as an alternative for the production of vegetables by farmers who have freshwater restriction, although with a reduction in the yield.

Key words: Lactuca sativa L., salinity, electrical conductivity.

Recebido para publicação em 08/06/2011 e aprovado em 22/12/2011

'Engenheira-Agrônoma. Doutora. Departamento de Horticultura, Universidade Tecnológica Federal do Paraná (UTFPR), Campus Dois Vizinhos, Estrada para Boa Esperança, Km 04, Caixa Postal 157, 85660-000, Dois Vizinhos, Paraná, Brasil. dalvaufsmdeutch@yahoo.com.br, "Autora para correspondência.

${ }^{2}$ Engenheiro Florestal. Mestrando em Solos, Departamento de Solos, Universidade Federal de Santa Maria, Avenida Roraima, Faixa de Camobi, Km 09, 97105-900, Santa Maria, Rio Grande do Sul, Brasil. epaulus2000@yahoo.com.br

${ }^{3}$ Engenheiro-Agrônomo. Doutor. Departamento de Horticultura, Universidade Tecnológica Federal do Paraná (UTFPR), Campus Dois Vizinhos, Estrada para Boa Esperança, Km 04, Caixa Postal 157, 85660-000, Dois Vizinhos, Paraná, Brasil. gilmarnava@utfpr.edu.br

${ }^{4}$ Licenciada em Economia Doméstica. Mestre. Universidade Tecnológica Federal do Paraná (UTFPR), Campus Dois Vizinhos, Estrada para Boa Esperança, Km 04, Caixa Postal 157, 85660-000, Dois Vizinhos, Paraná, Brasil. claudiaamkuhn@yahoo.com.br 


\section{INTRODUÇÃO}

A escassez de água no mundo é um problema diagnosticado, especialmente, em países com grandes regiões semiáridas como o Brasil. Diante do quadro de baixa oferta de água potável, tornam-se importantes os projetos de pesquisa e a geração de tecnologias que permitam o uso de águas salinas na produção de alimentos (Paulus et al.,2010).

O cultivo hidropônico representa uma alternativa ao cultivo convencional, com vantagens para o consumidor, para o produtor e para o ambiente, com a obtenção de produtos de alta qualidade, com ciclo curto, maior produtividade, menor gasto de água, de insumos agrícolas e de mão de obra. No Brasil, a alface (Lactuca sativa L) é a mais importante hortaliça produzida em sistema hidropônico NFT (fluxo laminar de nutrientes). O uso de soluções nutritivas, preparadas com água de baixa qualidade, ou o reuso de soluções nutritivas têm sido considerados possibilidades para essa cultura.

Em trabalhos realizados com alface em hidroponia, com utilização de água salina, Soares (2007) concluiu que, em hidroponia NFT, a tolerância à salinidade foi maior do que no solo.

Em cultivos hidropônicos, utilizando-se águas salinas, a salinidade do meio é definida pela condutividade elétrica da solução nutritiva. $\mathrm{O}$ aumento dessa condutividade ao longo do ciclo, em cultivos hidropônicos com alface, utilizando-se águas salobras para o preparo da solução nutritiva e para reposição da água evapotranspirada, foi observado por Alves et al., (2011), em Cruz das AlmasBA, Santos et al., (2010), em Ibimirim, PE, e Paulus et al. (2010), em Piracicaba, SP.

A salinidade do meio prejudica o desenvolvimento das plantas por diminuição do potencial osmótico da solução, o que se associa ao estresse hídrico pela dificuldade, decorrente, de absorver água do solo; do acúmulo de íons tóxicos nos tecidos $\left(\mathrm{Cl}^{-}, \mathrm{Na}^{+}\right)$e do desequilíbrio iônico. Em função desses fatores, o consumo hídrico da cultura pode ser modificado pela salinidade do meio (Rhoades et al, 2000).

A redução do consumo hídrico pelas plantas, nos níveis crescentes de salinidade, foi verificada por Gervásio et al., (2000) em alface, na região de Lavras, MG, com um déficit de evapotranspiração de $28 \%$, em plantas irrigadas com água nas concentrações de 0,18 a $6 \mathrm{dS} \mathrm{m}^{-1}$. Soares (2007) verificou redução de $17,5 \%$ do consumo hídrico em cultivos hidropônicos com alface, utilizando-se água salina para reposição da água evapotranspirada, em Piracicaba, SP.

A necessidade da realização de pesquisas com a utilização de águas salinas no preparo da solução nutritiva e na reposição da água evapotranspirada, para alface, justifica a importância da realização deste estudo, pois a utili- zação dessas águas na produção de hortaliças pode ser uma alternativa de renda para o agricultor que conte somente com a opção de água salina na propriedade. $\mathrm{O}$ objetivo do trabalho foi avaliar o crescimento, o consumo hídrico e a extração de nutrientes, por alface, em sistema hidropônico NFT, com a utilização de águas salinas no preparo da solução nutritiva e na reposição da lâmina diária evapotranspirada, ao longo do ciclo de cultivo.

\section{MATERIAL E MÉTODOS}

Os experimentos foram conduzidos em dois ciclos de cultivo, no período de agosto a outubro de 2007 e de dezembro de 2007 a janeiro de 2008, em ambiente protegido, em Piracicaba, SP. A casa de vegetação de $126 \mathrm{~m}^{2}$, modelo arco simples, foi coberta com filme transparente de polietileno de baixa densidade, com $0,10 \mathrm{~mm}$ de espessura e, nas laterais, por telas de $50 \%$ de sombreamento. As médias das temperaturas do ar no interior da casa de vegetação foram de $22^{\circ} \mathrm{C} \mathrm{e} 27,1^{\circ} \mathrm{C}$, no primeiro e segundo cultivos, respectivamente. As mínimas ficaram entre $14^{\circ} \mathrm{C}$ e $21,6^{\circ} \mathrm{C}$ e as máximas variaram de $23^{\circ} \mathrm{C}$ a $34^{\circ} \mathrm{C}$, durante o primeiro cultivo. No segundo cultivo, as mínimas variaram entre $18^{\circ} \mathrm{C}$ e $26,5^{\circ} \mathrm{C}$ e as máximas de $29,5^{\circ} \mathrm{C}$ a $38^{\circ} \mathrm{C}$. As condições ambientais foram próximas às ótimas $\left(15-25^{\circ} \mathrm{C}\right)$ para alface (Goto, 1998).

O cultivar de alface utilizado foi o Verônica, de coloração verde, do tipo crespa. As mudas foram produzidas em espuma fenólica, transplantadas para o berçário com sete dias e irrigadas com solução nutritiva (Furlani, 1998), diluída a $50 \%$, durante sete dias e, posteriormente, com solução nutritiva a $100 \%$, visando a sua adaptação ao cultivo com águas salinas.

O sistema utilizado foi o NFT, em que a solução nutritiva foi distribuída nos canais de cultivo, na vazão de 1,6 L por minuto, com frequência de irrigação programada para acionar a motobomba durante $15 \mathrm{~min}$, por $15 \mathrm{~min}$ desligada, no período diurno $(7 \mathrm{~h}-20 \mathrm{~h}$ ) e por 15 min ligada, a cada intervalo de $2 \mathrm{~h}$, no período noturno $(20 \mathrm{~h}-7 \mathrm{~h})$.

A solução nutritiva foi conduzida por bombeamento, por tubulação de PVC, do reservatório até a parte mais alta do canal de cultivo (polipropileno, com diâmetro comercial de $100 \mathrm{~mm}$ ) e retornava ao reservatório por gravidade. Para o armazenamento da solução nutritiva, na quantidade de $45 \mathrm{~L}$, foram utilizados reservatórios de plástico azul com capacidade de $60 \mathrm{~L}$. O espaçamento foi de $0,30 \mathrm{~m}$ entre linhas e 0,25 m entre plantas.

Para calcular o consumo hídrico por planta, utilizaramse depósitos de abastecimento automático, construídos com tubulação de PVC de seção contínua e diâmetro de $200 \mathrm{~mm}$. O depósito de abastecimento, contendo água salina, foi dotado de uma régua graduada, fixada a uma mangueira transparente. Esse tipo de sistema permitiu a 
saída automática de água salina para o reservatório de solução nutritiva, por uma válvula-boia, possibilitando a manutenção da solução nutritiva com água salina. O volume evapotranspirado diário por planta foi calculado, dividindo-se a água consumida no reservatório pelo número de plantas no canal de cultivo. A solução nutritiva utilizada foi elaborada com base em Furlani (1998), com condutividade elétrica próxima a $2,00 \mathrm{dS} \mathrm{m}^{-1}$ quando preparada com água de baixa salinidade $\left(0,20 \mathrm{dS} \mathrm{m}^{-1}\right)$. No primeiro ciclo de cultivo, a concentração da solução nutritiva foi de $100 \%$. No segundo ciclo de cultivo, no período de verão, a concentração da solução nutritiva foi de $75 \%$, com condutividade elétrica de $1,60 \mathrm{dS} \mathrm{m}^{-1}$.

O delineamento experimental foi em blocos ao acaso, sendo estudados os efeitos de cinco níveis de salinidade da água, utilizando-se $\mathrm{NaCl}$, testando-se as condutividades elétricas da solução nutritiva de 2,0 (testemunha), 3,$3 ; 5,8 ; 8,3$ e 10,4, no primeiro ciclo de cultivo, e 1,6 (testemunha), 3,0; 5,6; 8,2 e 10,6 $\mathrm{dS} \mathrm{m}^{-1}$ no segundo ciclo de cultivo. As quantidades de $\mathrm{NaCl}$ utilizadas nos tratamentos foram ( $\mathrm{g} \mathrm{L}^{-1} \mathrm{de} \mathrm{NaCl}$ ): 0; 0,585; 1,755; 2,925 e 4,095, para os dois ciclos de cultivo. As águas utilizadas para o preparo da solução nutritiva foram salinizadas, artificialmente, com adição de cloreto de sódio $(\mathrm{NaCl})$ à água doce, resultando em cinco níveis de salinidade da água. Por causa da alta disponibilidade volumétrica de solução nutritiva por planta, $3 \mathrm{~L}$, não foram realizadas reposições de nutrientes de solução nutritiva. Foram realizadas a cada três dias leituras da condutividade elétrica e de $\mathrm{pH}$ da solução nutritiva.

Aos 23 dias após o transplantio, foram colhidas quatro plantas centrais do perfil de cultivo, que foram separadas em partes aéreas e raízes, e, pesadas. Após a pesagem, foram levadas à estufa com circulação de ar, à temperatura de $65^{\circ} \mathrm{C}$, até massa constante para pesagem. Após a secagem, procedeu-se à moagem das folhas, para determinar os teores de nutrientes e possíveis acúmulos de elementos em níveis fitotóxicos, ou capazes de comprometer a segurança alimentar. Os teores de nutrientes nas folhas foram determinados conforme método proposto por Malavolta et al., (1997).

A área foliar foi determinada por um integrador de área, marca LI-COR modelo LI-3100.

Os resultados obtidos foram submetidos ao programa "SAS" (SAS, Institute, 1999). Os dados foram submetidos à análise de variância com teste $\mathrm{F}(\mathrm{p}<0,01)$ e aplicada a análise de regressão polinomial.

\section{RESULTADOS E DISCUSSÃO}

\section{Crescimento}

Nas condições em que os experimentos foram desenvolvidos, ao se utilizarem águas salinas no preparo da solução nutritiva e na reposição da perda por evapotranspiração da alface, verificou-se aumento da salinidade (CEsol.) da solução nutritiva, ao longo do ciclo (Figuras 1a e 1b). A salinização crescente explica-se pelo acúmulo de íons não absorvidos pelas plantas de alface e por causa da reposição, do volume de água evapotranspirado, com água salina. Este mesmo comportamento foi observado por Alves et al., (2011) e por Santos et al., (2010), em avaliação de alface com águas salinas, no preparo da solução nutritiva e na reposição da perda por evapotranspiração. A condutividade elétrica da testemunha (água não salina) apresentou redução da salinidade da solução nutritiva, em decorrência do consumo de nutrientes, que foi superior ao acúmulo de sais dissolvidos na água.

Observou-se efeito significativo da salinidade sobre o crescimento da alface cv. Verônica. Para as variáveis número de folhas, massa de matéria fresca das folhas e massa de matéria fresca da parte aérea, o efeito foi linear, no primeiro e no segundo cultivo (Figuras 2a, 2b, 2c, 2d, 2e, 2f). O mesmo comportamento foi observado para a massa de matéria seca das folhas e massa de matéria seca da parte aérea, no primeiro e segundo cultivo (Figuras 3a, 3b, 3c, 3d). Para massa de matéria seca das raízes, no primeiro cultivo houve diferença significativa, a equação que se ajustou foi quadrática (Figura 3e). Para o segundo cultivo não houve diferença significativa para massa de matéria seca das raízes, sendo o valor médio de 2,53 (Figura 3f).

No primeiro e segundo cultivo, para cada aumento unitário da salinidade da água $\left(\mathrm{dS} \mathrm{m}^{-1}\right)$, as estimativas de reduções percentuais da massa de matéria fresca da parte aérea foram de 6,0 e 6,5\%, respectivamente, em relação às da solução nutritiva sem água salina (2,00 e 1,60 dS m-1). Para massa de matéria seca, as reduções percentuais foram de 7,5 e 4,6\%, no primeiro e segundo cultivo, respectivamente. A redução da massa de matéria fresca da parte aérea está relacionada com o número de folhas, que seguiu tendência linear com o incremento da salinidade.

Os valores das perdas relativas encontradas neste estudo são próximos dos registradas por Alves et al., (2011), para o cultivar Verônica, nas condições de Cruz das Almas, Bahia, que foram de 7,0 \%. Por outro lado, Santos et al., (2010), utilizando águas salobras de origem subterrânea, nas condições de Ibimirim, Pernambuco, encontraram uma redução ainda maior, de 17,06\% (dS m $\left.{ }^{-1}\right)$ para alface crespa "Vera".

Em trabalhos conduzidos em hidroponia, com o mesmo cultivar, porém, somente utilizando águas salinas para reposição da perda por evapotranspiração, Soares (2007) reporta baixa redução de $2,27 \%$, o que, pelo autor, foi avaliado como moderado efeito da salinidade da água para massa de matéria fresca da parte aérea. 
O aumento de salinidade da solução com a utilização de água salina não afetou significativamente a massa de matéria seca da raiz no segundo cultivo, o que permite afirmar que a redução do crescimento das plantas pode ser explicada pelo efeito da salinidade sobre a parte aérea, mais do que sobre o sistema radicular (Alves et al., 2011). Soares (2007) também não verificou efeito da salinidade da água sobre o sistema radicular da alface "Verônica" em hidroponia NFT.

Com relação à massa de matéria fresca da parte aérea (MFPA), verificou-se perda de 56,16 e 63,92\%, no primeiro e segundo cultivo, respectivamente, ao se comparar o nível mais elevado de salinidade (10,4 e 10,6 dS m ${ }^{-1}$ ) com o da testemunha (Figura 2). Para uma redução de produtividade da massa de matéria fresca da parte aérea inferior a $11 \%$, o produtor de alface poderá utilizar água salina com condutividade elétrica até $1,80 \mathrm{dS} \mathrm{m}^{-1}$.

Mesmo com redução da produção relativa no nível mais alto de salinidade, é viável a produção. Os agricultores não estão utilizando água salina por falta de informação sobre a viabilidade da utilização dessas águas (Paulus et al., 2010). Como alternativa, o produtor pode compensar a redução da produção relativa, aumentando a população de plantas (Alves et al., 2011).

Analisando a qualidade comercial da alface cv. Verônica verificou-se que a alface produzida no primeiro e segundo cultivo, nos diferentes níveis de salinidade não apresentou injúrias severas que pudessem afetar o preço de venda; portanto, toda a massa de matéria fresca foi considerada como produtividade comercial.

Foi observada redução linear da área foliar com o aumento da salinidade (Figuras $3 \mathrm{~g}$ e $3 \mathrm{~h}$ ). A redução percentual por incremento unitário de condutividade elétrica foi de 5,9 e 6,2\%, no primeiro e segundo cultivo.
O efeito da salinidade sobre o crescimento pode estar relacionado com a redução da área foliar, a qual afeta a assimilação de carbono pela planta que, por sua vez, conduz uma menor taxa fotossintética (Munns, 1993). Greenway \& Muns (1980) sugerem que a salinidade exerce efeito direto sobre a expansão ou divisão da célula, e o efeito principal da salinidade ocorre sobre a redução da área foliar, o que diminui a área destinada ao processo fotossintético, limitando a produção de fotoassimilados pela planta e reduzindo a sua capacidade produtiva (Munns \& Termaat,1986).

A redução do crescimento foliar sob estresse hídrico pode ser um mecanismo de sobrevivência, que permite a conservação de água. Contudo, não necessariamente é o caso do estresse salino, pelo qual a disponibilidade da água para o crescimento em geral não é limitante, à medida que o gradiente de potencial hídrico favorece a absorção, em virtude da osmoregulação. Desta forma, a redução na área foliar, como consequência do estresse salino, pode representar a inabilidade das plantas para discriminar entre os estresses hídrico e salino (Binzel et al., 1985), em lugar de um mecanismo de adaptação (Greenway \& Munns, 1980).

No presente estudo, o número de folhas foi afetado pela salinidade da água. A diminuição do número de folhas foi observada em hidroponia conduzida em substrato (fibra de coco), em dois cultivares de alface (Severus e Ballerina), sob salinidade da solução nutritiva causada por $\mathrm{NaCl}$ (Miceli et al., 2003). Por outro lado, Andriolo et al. (2005) não observaram efeito da salinidade sobre o número de folhas de alface 'Vera'. A resposta das plantas ao meio salino depende de suas características genéticas e das condições do meio, podendo cultivares diferentes apresentarem respostas distintas à salinidade (Gorham et al., 1988).

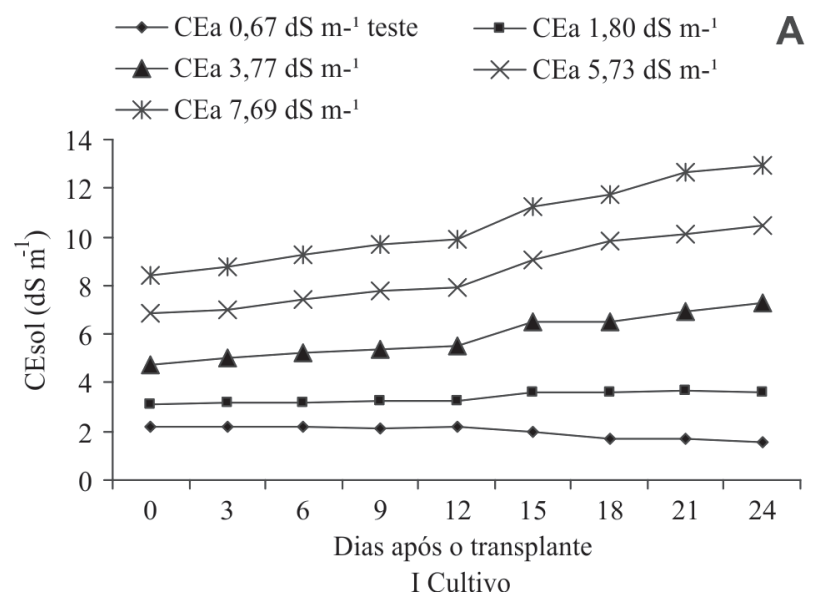

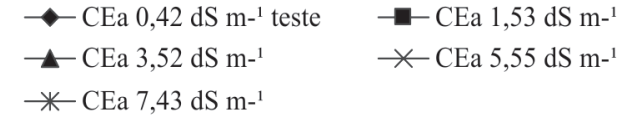

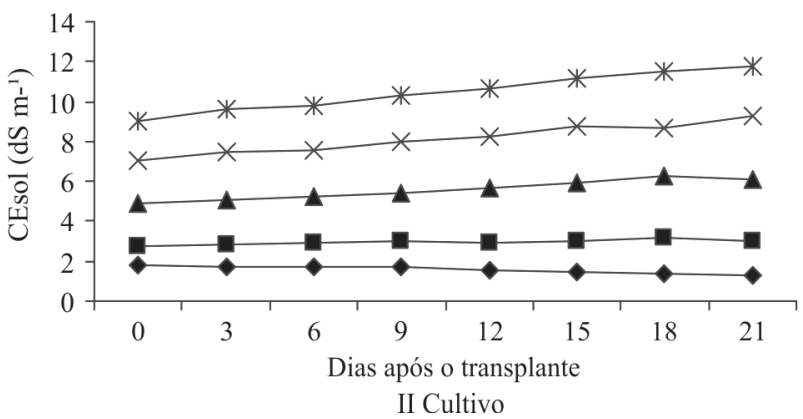

Figura 1. Evolução da condutividade elétrica da solução nutritiva (CEsol) ao longo do primeiro cultivo (a) e segundo cultivo (b) da alface, cv. Verônica, em sistema hidropônico NFT, utilizando-se água salina no preparo da solução nutritiva e na reposição da evapotranspiração. 


\section{Consumo hídrico}

Verificou-se que, com o aumento da salinidade, a evapotranspiração decresceu no primeiro e segundo cultivo, sendo que esse decréscimo foi ajustado por um modelo linear (Figuras 3i e 3j). De acordo com as equações de regressão, a redução percentual da evapotranspiração, em relação à solução nutritiva sem água salina, foi de 3,9 e $10,0 \%$, por incremento unitário da condutividade elétrica, no primeiro e no segundo cultivo, respectivamente.

No nível mais alto de salinidade $\left(10,4 \mathrm{dS} \mathrm{m}^{-1}\right)$, o consumo de água, no primeiro cultivo, foi 37,0\% menor, em rela-
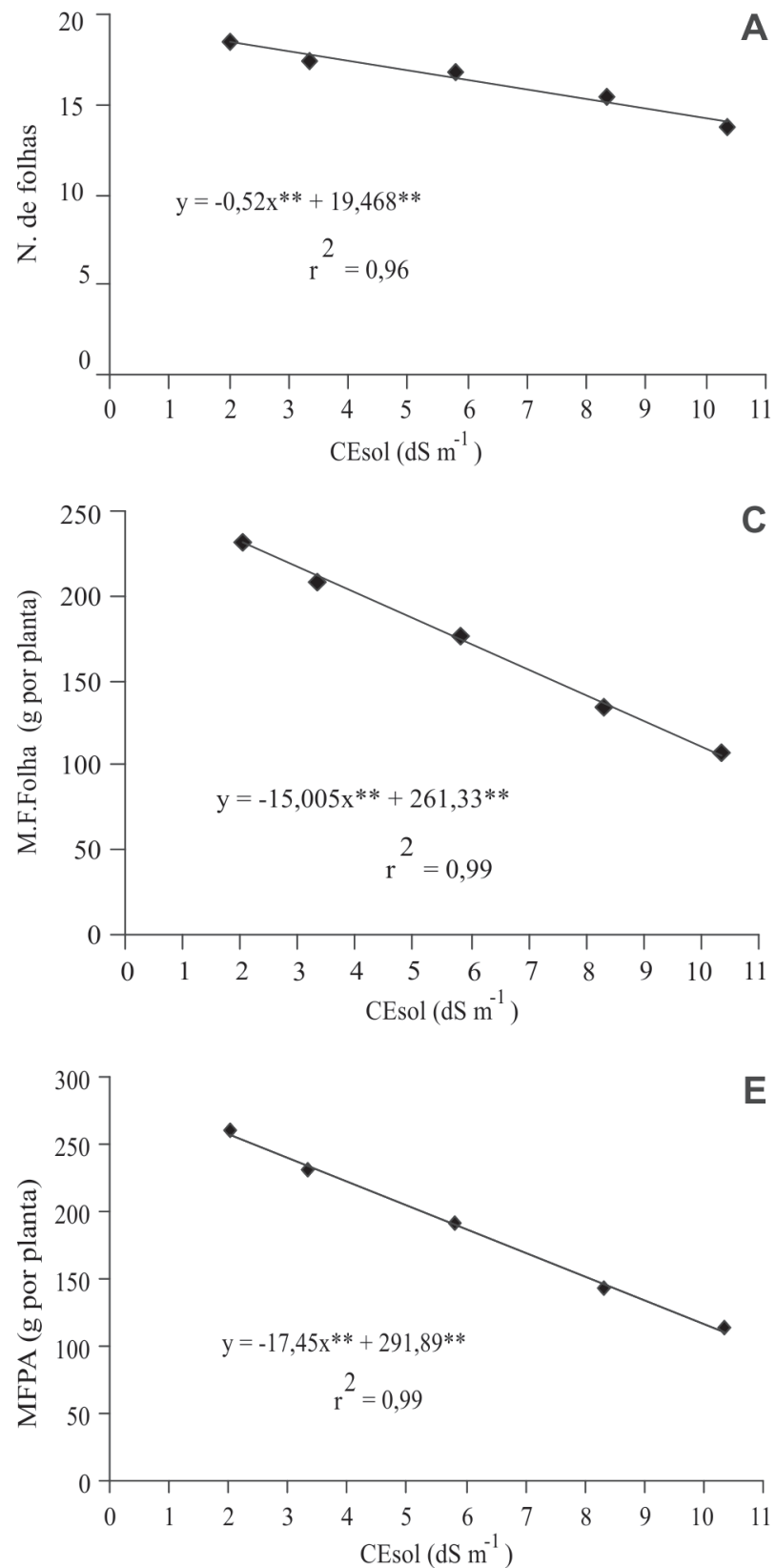

(**) representam significativo a $\mathrm{p}>0,01$.

Figura 2. Número de folhas (a), (b); massa de matéria fresca das folhas (M.F.F.) (c), (d); e massa de matéria fresca da parte aérea (MFPA) (e), (f) obtidos no primeiro e segundo cultivos da alface cv. Verônica, conduzida em sistema hidropônico NFT, em função da salinidade.

Rev. Ceres, Viçosa, v. 59, n.1, p. 110-117, jan/fev, 2012

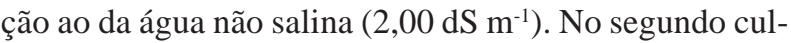
tivo, foi 45,3\% inferior, em relação ao da água não salina $\left(1,6 \mathrm{dS} \mathrm{m}^{-1}\right)$. Possivelmente, o efeito osmótico da salinidade reduziu a disponibilidade de água para a planta, contribuindo com o estresse hídrico, com redução progressiva da superfície transpiratória (Richards, 1974).

Em sistema hidropônico, Soares (2007) reporta a diminuição linear do consumo hídrico em função do aumento da salinidade da água de reposição. O autor encontrou redução de $17,5 \%$ no consumo hídrico para a água com $7,46 \mathrm{dS} \mathrm{m}^{-1}$. A redução do consumo de água pelas plantas
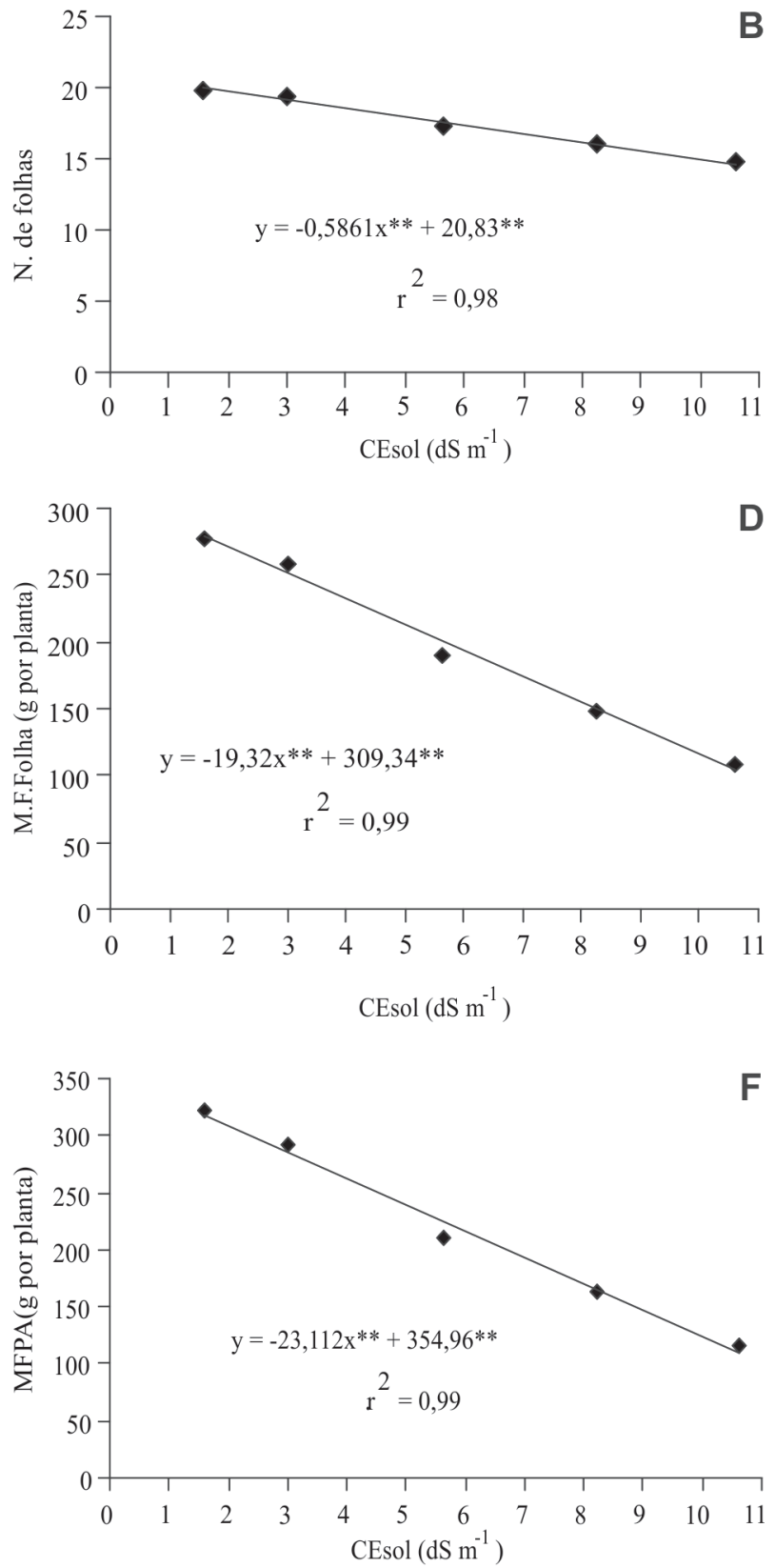

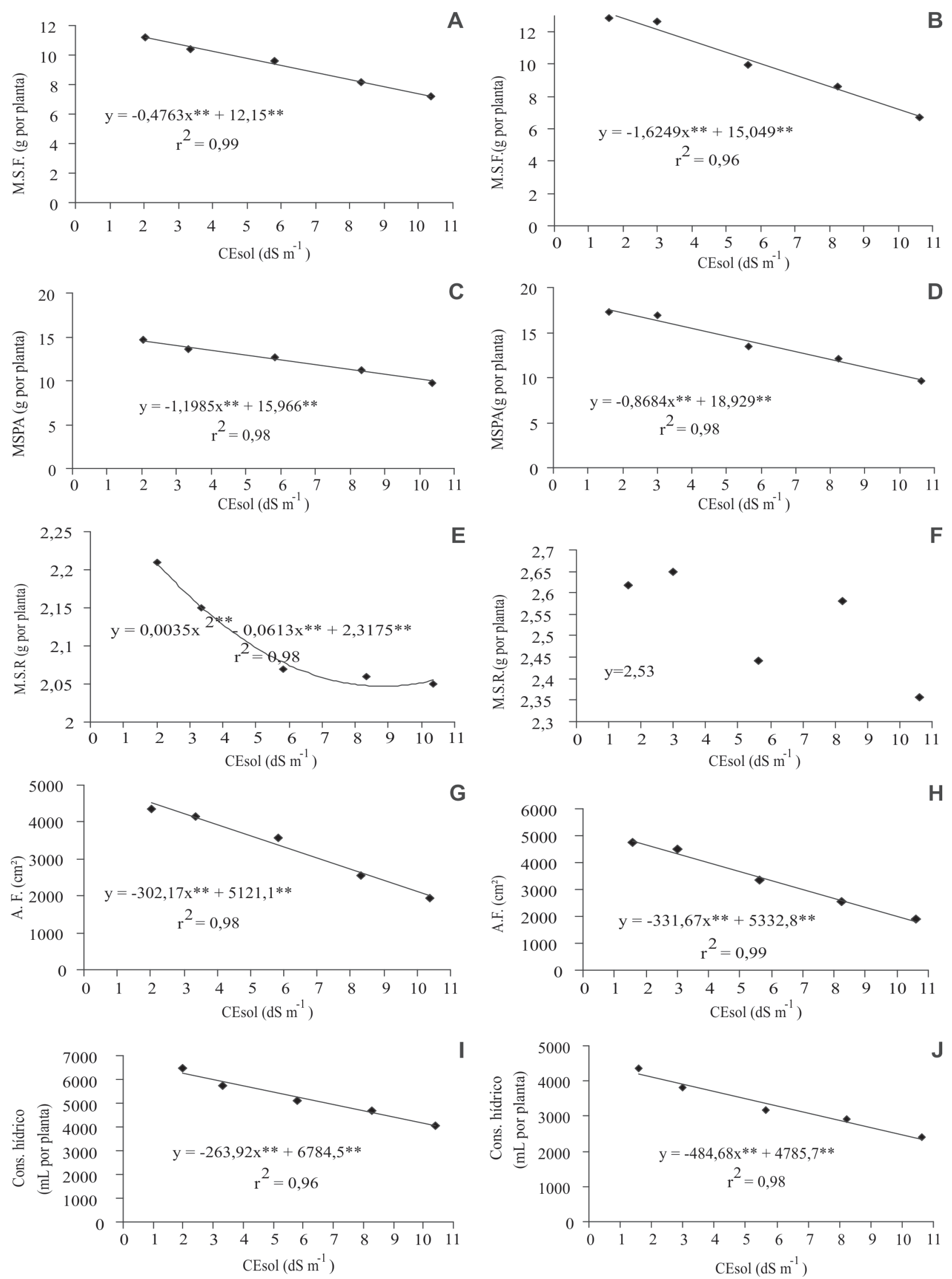

(**) representam significativo a $\mathrm{p}<0,01$.

Figura 3. Massa de matéria seca das folhas (MSF) (a), (b); massa de matéria seca da parte aérea (MSPA) (c), (d) e massa de matéria seca das raízes (MSR) (e), (f); área foliar (AF) (g), (h); consumo hídrico (i), (j) no primeiro e segundo cultivos da alface cv. Verônica, em sistema hidropônico NFT, em função de diferentes níveis de salinidade. 
com o aumento da salinidade também foi verificada por Viana et al., (2004), em mudas de alface da variedade Elba, cultivadas em vasos.

\section{Nutrição mineral}

Durante o cultivo não foram observados sintomas de deficiência mineral nas plantas de alface (Tabela 1). Um dos benefícios do sistema NFT para as plantas é a passagem da solução nutritiva apenas pela zona radicular, sem ocasionar molhamento das folhas. Isso evita a absorção foliar, que faz com que íons tóxicos acumulem-se nas folhas, ocasionando sintomas de injúrias foliares, como queima de bordos e do limbo foliar, sintomas esses de plantas submetidas à salinidade (Santos et al., 2010).

No primeiro ciclo de cultivo, as concentrações de potássio, cálcio e magnésio da parte aérea de alface cv. Verônica decresceram com o aumento da salinidade da água. As concentrações de nitrogênio, fósforo, enxofre e boro não foram influenciadas pela salinidade. Para o potássio, cálcio e magnésio, o aumento do nível de salinidade de 2,00 dS m ${ }^{-1}$ para $10,4 \mathrm{dS} \mathrm{m}^{-1}$ resultou em decréscimo na concentração, de 51,60 e 42\%, respectivamente.

No segundo ciclo de cultivo, as concentrações de nitrogênio, fósforo, potássio e enxofre não foram influenciadas pela salinidade da água. Porém, as concentrações de cálcio, magnésio e boro diminuíram com aumento da salinidade da água. A concentração de cloro e de sódio aumentaram de forma significativa com os níveis de salinidade.

Fernandes et al., (2002), estudando o acúmulo de macronutrientes e sódio em pupunheira, constataram redução na absorção de potássio, quando se adicionou sódio na solução nutritiva, atribuindo esse efeito ao antagonismo existente entre esses cátions.

A concentração de cálcio diminuiu com o incremento da salinidade. De acordo com Cramer et al., (1994), a ele- vação da concentração de sódio na solução nutritiva acarretou reduções na concentração de cálcio em plantas de milho submetidas a diferentes níveis de salinidade. Dessa forma, é provável que a redução na concentração de cálcio tenha sido um dos fatores que afetaram o metabolismo e, consequentemente, reduziram o crescimento, nos níveis mais elevados de salinidade.

O comportamento da concentração de magnésio nas plantas foi bastante semelhante ao da concentração do cálcio, quando foram submetidos a aumentos sucessivos das concentrações de cloreto de sódio na solução nutritiva. Azevedo Neto et al.(1995), trabalhando com sorgo, reportaram que as concentrações de magnésio podem permanecer constantes ou diminuir, na parte aérea, com o incremento do estresse salino. Esta variabilidade de resultados realça a importância de maiores estudos sobre a influência da salinidade sobre a concentração deste macronutriente nos diferentes tecidos vegetais.

A análise das concentrações de nitrogênio, fósforo, potássio, cálcio, magnésio e enxofre na parte aérea das plantas de alface demonstrou que todos esses macronutrientes estavam dentro das faixas de concentrações adequadas para a cultura da alface, estabelecidas por Raij (1997).

O incremento do nível de salinidade na água determinou aumentos significativos nas concentrações de sódio e de cloro nas folhas. As concentrações de cloro foram superiores às de sódio, por sua mobilidade e transporte elevado como ânion livre na planta (Marschner, 1995). Fernandes et al. (2002) também verificaram maior acúmulo de cloro do que de sódio em pupunheira, em condições salinas.

$\mathrm{Na}$ alface, os sintomas de toxidez por sódio foram evidenciados pelo nanismo das plantas, as folhas coriáceas com coloração verde mais intensa e a redução da área foliar com o aumento da concentração salina. Soares

Tabela 1. Concentração foliar de nitrogênio, fósforo, potássio, cálcio, magnésio, enxofre, cloreto, boro e sódio na alface cv. Verônica, conduzida em sistema hidropônico em função da salinidade da solução nutritiva em dois cultivos

\begin{tabular}{|c|c|c|c|c|c|c|c|c|c|c|}
\hline \multicolumn{6}{|c|}{ Cultivo I } & \multicolumn{5}{|c|}{ Cultivo II } \\
\hline \multicolumn{11}{|c|}{ C.E. $\left(\mathrm{dS} \mathrm{m}^{-1}\right)$} \\
\hline $\begin{array}{l}\text { Nutri. } \\
\left(\mathrm{g} \mathrm{kg}^{-1}\right)\end{array}$ & 2,0 & 3,3 & 5,8 & 8,3 & 10,4 & 1,6 & 3,3 & 5,6 & 8,2 & 10,6 \\
\hline $\mathrm{N}$ & $39 a^{*}$ & $38 \mathrm{a}$ & $40 \mathrm{a}$ & $38 \mathrm{a}$ & $38 \mathrm{a}$ & $41 \mathrm{a}$ & $40 \mathrm{a}$ & $39 a$ & $38 \mathrm{a}$ & $37 a$ \\
\hline$P$ & $8,7 \mathrm{a}$ & $8,8 \mathrm{a}$ & $9,0 \mathrm{a}$ & $9,2 \mathrm{a}$ & $8,6 \mathrm{a}$ & $6,9 \mathrm{a}$ & $7,4 a$ & $7,7 \mathrm{a}$ & $8,1 \mathrm{a}$ & $7,8 \mathrm{a}$ \\
\hline K & $56 \mathrm{a}$ & $48 b$ & $43 b$ & $29,2 \mathrm{c}$ & $27 \mathrm{c}$ & $54 \mathrm{a}$ & $32 \mathrm{a}$ & $43,8 \mathrm{a}$ & $42 a$ & $37 \mathrm{a}$ \\
\hline $\mathrm{Ca}$ & $13,5 \mathrm{a}$ & $10 \mathrm{~b}$ & $7,5 \mathrm{c}$ & $6,7 \mathrm{c}$ & $5,5 \mathrm{~d}$ & $12 \mathrm{a}$ & $9,6 \mathrm{~b}$ & $7,4 \mathrm{c}$ & $7,1 \mathrm{c}$ & $6,5 \mathrm{c}$ \\
\hline $\mathrm{Mg}$ & $3,3 \mathrm{a}$ & $2,5 b$ & $2,1 \mathrm{c}$ & $1,9 \mathrm{c}$ & $1,9 \mathrm{c}$ & $2,5 \mathrm{a}$ & $2,2 b$ & $1,8 \mathrm{c}$ & $1,8 \mathrm{c}$ & $1,9 \mathrm{c}$ \\
\hline S & $1,5 \mathrm{a}$ & $1,6 \mathrm{a}$ & $1,5 \mathrm{a}$ & $1,6 \mathrm{a}$ & $1,4 \mathrm{a}$ & $2,7 \mathrm{a}$ & $2,8 \mathrm{a}$ & $2,7 \mathrm{a}$ & $2,8 \mathrm{a}$ & $2,9 a$ \\
\hline $\mathrm{Cl}$ & $18 \mathrm{~d}$ & $25 \mathrm{c}$ & $30 \mathrm{~b}$ & $41 \mathrm{a}$ & $42 a$ & $12 \mathrm{e}$ & $19 d$ & $29 \mathrm{c}$ & $40 \mathrm{~b}$ & $54 \mathrm{a}$ \\
\hline B & $37,5 \mathrm{a}$ & $33 a$ & $33 a$ & $35 a$ & $38 \mathrm{a}$ & $19 \mathrm{c}$ & $20 \mathrm{~b}$ & $22,5 b$ & $25 \mathrm{a}$ & $28 \mathrm{a}$ \\
\hline $\mathrm{Na}$ & $4,2 \mathrm{c}$ & $15 \mathrm{c}$ & $26 \mathrm{~b}$ & $32,8 \mathrm{a}$ & $32 a$ & $4 d$ & $12 \mathrm{c}$ & $28 b$ & $34 \mathrm{a}$ & $38 \mathrm{a}$ \\
\hline
\end{tabular}

*Médias, seguidas de mesmas letras nas linhas ,não diferem entre si pelo teste de Tukey, p $<0,01$. 
(2007), em trabalhos com alface Verônica, relata que plantas submetidas aos níveis de salinidade mais elevados $\left(9,08 \mathrm{dS} \mathrm{m^{-1 }}\right)$ apresentaram coloração verde escura.

Os resultados obtidos sugerem não ter havido mecanismos de exclusão dos íons tóxicos $\left(\mathrm{Na}^{+}\right.$e $\left.\mathrm{Cl}^{-}\right)$, após o processo de absorção, o que pode ser explicado por seu acúmulo na parte aérea. Essas respostas resultaram, provavelmente, de alteração no balanço osmótico, na perda de turgescência das células-guarda, o que condiz com a redução generalizada da atividade metabólica da planta (Gorham et al., 1988).

\section{CONCLUSÃO}

A utilização de água salobra, no preparo da solução nutritiva e na reposição da lâmina diária evapotranspirada, resultou na redução do crescimento e do consumo hídrico da alface "Verônica", com o aumento da salinidade da água.

Não foram observados sintomas de deficiência mineral nas plantas de alface.

O incremento do nível de salinidade na água determinou aumentos significativos nos teores de $\mathrm{Na}$ e $\mathrm{Cl}$ nas folhas.

\section{REFERÊNCIAS}

Alves MS, Soares TM, Silva LT, Fernandes JP, Oliveira MLA \& Vital PS. (2011) Estratégias de uso de água salobra na produção de alface em hidroponia NFT. Revista Brasileira de Engenharia Agrícola e Ambiental, 15:491-498.

Andriolo JL, Luz GL, Witter MH, Godói RS, Barros GT \& Bortoloto OO (2005) Growth and yield of lettuce plants under salinity. Horticultura Brasileira, 23:931-934.

Azevedo Neto AD; Barreto LP \& Bezerra Neto E (1995) Efeito da salinidade sobre os teores de macronutrientes em duas cultivares de sorgo cultivadas em solução nutritiva. In: $25^{\circ}$ Congresso Brasileiro da Ciência do Solo, Viçosa. Resumos expandidos. SBCS, p.1345-1347.

Binzel ML, Hasegawa PM, Handa AK \& Bressan RA (1985) Adaptation of tabacco cells to $\mathrm{NaCl}$. Plant Physiology, 29:118125

Cramer GR, Alberico GJ \& Schmidt C (1994) Salt tolerance is not associated with the sodium accumulation of two maize hybrids. Australian Journal of Plant Physiology, 21:675-692.

Fernandes AR, Carvalho JG, Curi N, Pereira Pinto JEB \& Gontijo Guimarães PT (2002) Nutrição mineral de mudas de pupunheira sob diferentes níveis de salinidade. Pesquisa Agropecuária Brasileira, 37:1613-1619.

Furlani PR. (1998) Instruções para o cultivo de hortaliças de folhas pela técnica hidroponia NFT. Campina, Instituto Agronômico. 30 p. (Boletim técnico 168).

Gervásio, E S, Carvalho J A \& Santana M J. (2000) Efeito da salinidade da água de irrigação na produção da alface americana. Revista Brasileira de Engenharia Agrícola e Ambiental, 4:125128

Goto R (1998) A cultura da alface. In: Goto R \& Tivelli SW (Ed.). Produção de hortaliças em ambiente protegido: condições subtropicais. São Paulo, FUNEP. p.137-159.
Gorham J, Tomar OS \& Wyn Jones RG (1988) Salinity induced changes in the chemical composition of Leucaena leucocephala and Sesbania bispinosa. Plant Physiology, 132:678-682.

Greenway H \& Munns R. (1980) Mechanisms of salt tolerance in nonhalophytes. Annual Review of Plant Physiology, 31:149190.

Malavolta E, Vitti GC \& Oliveira SA (1997). Avaliação do estado nutricional das plantas: princípios e aplicações. 2.ed. Piracicaba, POTAFOS. 201p

Marschner H. (1995) Mineral nutrition of higher plants. $2^{\mathrm{a}}$ ed. London, Academic Press. 889p.

Miceli A, Moncada A \& D'Anna F. (2003) Effect of salt stress in lettuce cultivation. Acta Horticulturae, 609:371-375.

Munns R (1993) Physiological processes limiting plant growth in saline soils: some dogmas and hypotheses. Plant, Cell and Environment, 16:15-24.

Munns R \& Termaat A (1986).Whole-plant responses to salinity. Australian Journal of Plant Physiology, 13:143-160.

Paulus D, Dourado Neto D, Frizzone JA \& Soares TM (2010) Produção e indicadores fisiológicos de alface sob hidroponia com água salina. Horticultura Brasileira, 28:29-35.

Raij BV. (Ed.) (1997) Recomendações de adubação e calagem para o Estado de São Paulo (Boletim 100). 2 ed. Campinas, Instituto Agronômico \& Fundação IAC. 285p.

Richards LA (1974) Diagnostico y rehabilitacion de suelos salinos y sódicos. DAEUA. México. Editorial Limusa, 172p.

Rhoades JD, Kandiah A \& Mashali AM (2000) Uso de águas salinas para produção agrícola. Tradução de Gheyi HR; Sousa JR de \& Queiroz JE. Campina Grande,UFPB, 117p. (Estudos FAO Irrigação e Drenagem, 48).

Santos RS, Dias NS, Sousa Neto ON \& Gurgel MT (2010) Uso do rejeito da dessalinização de água salobra no cultivo da alface (Lactuca sativa L.) em sistema hidropônico NFT. Ciência e Agrotecnologia, 34:983-989.

Soares TM (2007) Utilização de águas salobras no cultivo da alface em sistema hidropônico NFT com alternativa agrícola condizente ao semi-árido brasileiro. Tese de Doutorado. Escola Superior de Agricultura "Luiz de Queiroz", Universidade de São Paulo, Piracicaba, 267p.

Viana SBA, Fernandes PD, Gheyi HR, Soares FAL \& Carneiro PT (2004) Índices morfofisiológicos e de produção de alface sob estresse salino. Revista Brasileira de Engenharia Agrícola e Ambiental, 8:23-30. 